\title{
Potency of Enzymes from Renal Tubules as Biotracers in Rheumatoid Arthritis Patients Treat With Most Used Antirheumatic Drugs
}

\author{
Dejan Spasovski \\ University Clinic of Rheumatology1, "Ss Ciryl and Methodius” University, Skopje, Republic of Macedonia \\ "Corresponding Author: Dejan Spasovski, University Clinic of Rheumatology1, "Ss Ciryl and Methodius" \\ University, Skopje, Republic of Macedonia, E-mail: drspasovski@yahoo.co.uk; Tel: +389023147-668
}

Received: 01 October 2016; Accepted: 10 November 2016; Published: 15 November 2016

\begin{abstract}
Aim: To estimate the effect of initial therapy with Paracetamol and Ketoprofen on glomerular and tubular integrity in patients with Rheumatoid arthritis (RA), to quantify the toxicity of these drugs through measurements of the enzyme excretion that correlates with the damage degree on the tubular epithelium. Microalbuminuria is used as a marker for glomerular damage, and the urinary excretion of N-Acetyl- $\beta$-D-glucozaminidase (NAG) as an indicator of proximal tubular damage. To determine if there is a change in the clinical indicators of renal function (serum urea and creatinine, urine urea and creatinine, glomerular filtration rate - GFR) in the course of disease and if that change correlates with the dynamics of the quantity of excreted enzymes in urine, reactants of the acute pfase and index of disease activity (DAS28).
\end{abstract}

Methods: Using the colorimetric method for the determination of NAG, as well as immunoturbidimetric immunoturbidimetric assay for detection of microalbuminuria, we examined samples of 70 participants (35 RA pts treated only with Paracetamol, 35 RA pts treated with Ketoprofen), followed up in five time intervals in the course of 24 weeks. Rheumatoid factor (RF) is determined by the agglutination test (Lateks RF test) in the same participants.

Results: there is a weak correlation between NAG and microalbuminuria $(\mathrm{r}=0.16)$ in the group of patients treated with Paracetamol, while in the group treated with Ketoprofen there is a moderate correlation $(\mathrm{r}=0.28)$. NAG Arch Clin Biomed Res 2016; 1 (1): 20-31 
enzymuria in range, in number of examined patients and in the time of appearance is greater and appears earlier in the group with Ketoprofen compared with the group of Paracetamol.

Conclusions: Ketoprofen is a more potent NAG inductor and triggers greater tubular enzymuria than Parcetamol.

Keywords: N-acetyl- $\beta$-D-glucosaminidase; Microalbumin; Rheumatoid arthritis; Paracetamol; Ketoprofen

\section{Introduction}

The use of drugs in the treatment of Rheumatoid arthritis (RA) aims to shorten disease duration and prevent complications. Treatment with basic drugs somehow fulfil the expectations. There are a lot of findings recently which show that drugs can damage certain organs caused by their toxic effect due to their accumulation in the organs.

A lot of experiments were realized in the previous two decades, aiming to follow the toxic effect of pharmacotherapy to kidneys. These results are used as a base to follow up the influence of drugs in different kidney diseases. In these experiments, beside immunologic, radiologic and cytologic analyses, an important role play also biochemical analyses for detection of certain pathologic conditions caused in the course of treatment.

Among them, determination of enzymes' and their isoenzymes activity in the serum, urine and renal tissue has an important role.

Very often, therapeutic drugs (NSAIDs, Drugs that modify disease activity - DMRADs, Paracetamol, immunosuppressive and cytotoxic drugs), can have some nephrotoxic effect. The drug dose very often is not adjusted according to the patient's condition that can cause some unwanted effects, especially those related to kidney failure due to the their kidney accumulation. This can be seen in long term RA therapy.

Experiments done so far show that there is no indicator, traser or marker that reveals on time the nephrotoxicity caused in the course of disease. Efforts are made to detect these secondary (unwanted) effects by analysis of certain enzyme's activity in the urine.

\subsection{Diagnostic and Prognostic Significance of Biotracers}

In the contemporary medicine, there is a tendency to find the most specific and most sensitive biomarkers as disease indicators and diagnostic tools for follow up of successful treatment. A lot of investigation has been made in order to choose potential biomarkers that would be important in the clinical practice, giving the best diagnostic information. Especially important were their analytical and clinical application and their cost-benefit. Useful biomarker has to fulfil some criteria:

1.To have relatively high tissue-specific concentration, and low concentration in other tissues.

2. To be adequately distributed subcellularly, so, after the cell damage to be found easily in the examined fluid.

3. To be constant long enough in order to be suitable for following its concentration. 
4. To be able to be detected with sensitive analytical methods.

5. To be determined the cut-off values, taking in consideration clinical sensitivity and specificity.

\subsection{Renal Markers for Estimation of Renal Disfunction}

Urine enzymes could originate from plasma, lymph nodes of the urinary tract, epithelial cells of the urinary tract, white blood cells, red blood cells and kidneys. There are about 40 diffrent enzymes belonging to different groups: oxidoreductases, transferases, hydrolases, lyases. Only isomerases and ligases are not found in urine. Such great amount of enzymes in the urine shows the dominant role of the kidney in their excretion.

Several classes of measurable proteins in urine are used for estimation of the nephrotoxicity.

1. Enzyme with high molecular weight, that is not usually filtrated in the glomerulus, originating from the proximal tubule (microsomal AAP, NAG, $\gamma$-GT)

2. Intermediary proteins that are usually filtrated in the glomerulus in very small amounts are reapsorbed in the tubules in a great amount (microalbumin, transferrin).

3.Low molecular weight proteins that are normally filtered in the glomerulus and are reabsorbed in the tubules ( $\beta 2$ microglobulin).

According to their subcellular location these enzymes could be divided in membranous (AAP, $\gamma$-GT,AF), lysosomal

(NAG, $\beta$-GLU, $\beta$-GAL, lysozyme), mitochondrial (MDH, $\gamma$-LDH), cytoplasm (LDH). With the development of histochemistry a detailed insight was made in the enzyme distribution in different nephron structures. Their presence is lower in glomerules than in tubules. The specific enzyme distribution in the nephron enables detection of the spot that is damaged as a sequel of nephrotoxic agents. Examination of the cell membranes of the brush epithelium of the proximal tubules prove the localization of the alanine amnopeptidase (AAP) in 90\%, Alkaline phosphatase (AP) in $70 \%$ and $\gamma$-glutamyl transpeptidase $(\gamma-\mathrm{GT})$ in $50 \%$ of the whole enzyme activity in the kidney. The examinations reveal that tubular part of the nephron is rich with enzymes. Brush border is very sensitive in changes in their physiological status, so the release of the superficial enzymes could be used as a marker in primary and secondary renal impairments due to different drugs and toxins $[1,2]$.

Of all the urinary enzymes, U-NAG (urinary) is the most examined. It is the enzyme which belongs to the class of hydrolases present in a great amount in the lysosomes in the proximal tubular cells [8]. In the human body and biological fluids there are two major enzyme forms: A (Acid) i B (Basic ) [3-5]. Percentage of A isoform (U-NAGA) is the greatest in the normal urine [6,7].

At the end of the cell maturation process it is found in soluble form in the cytosol. That's why its excretion is connected with the exfoliative turnover and is noted as functional enzymuria. B isoform (U-NAG-B) depends on the matuation and is closely connected with the basal membrane in which it is present. Due to this location of B isoform (U-NAG-B), it is massively released in the tubular lumen only in the case of cytolytic tubular lesion. Its presence in the urine correlates with the cell lysis and is marked as lesion enzymuria. $[8,9]$. NAG could be detected also in the circulation. But, plasma NAG could not pass over intact glomerular membrane because of its high molecular weight 
(140.000 daltons). For that reason, in healthy individuals the urinary NAG is result of the enzyme amount released from the renal tubular cells [10] and is very sensitive marker for renal tubular damage.

\subsection{Urine albumin (Microalbuminuria)}

Albumin (molecular weight - $66 \mathrm{KDa}$ ) is quantitatively the most important plasma and urine protein. Approximately $30 \%$ of urine proteins belong to albumin, and it is a good indicator for estimation of the changes in glomerular permeability. Such changes happen in patients with diabetic and hypertensive nephropathy, nephritic syndrome, preeclampsia and glomerulonephritis. Urine albumin excretion has high individual variability and depends on the physical activity and food variations. From the pathophysiological point of view microalbuminuria could be caused by the increased glomerular permeability for albumin, increased glomerular pressure and/or decreased tubular albumin reabsorption. Renal endothelium is intimately involved in the regulation of these processes $[15,16]$.

\subsection{Renal Impairment due to Use Of Paracetamol And Ketoprofen}

If the drug is transported in proximal tubules via pinocytosis, than the hypothesis that nephrotoxicity is caused by lysosomal dysfunction due to the drug precipitation in lysosomes is proved. Vacuoles fulfilled with proteins are transported into the middle part of the cell, where they are unite with the existing lysosomes. Hydrolytic enzymes catabolize it and the new products are suitable for recirculation.

In the mechanism of Methotraxate nephrotoxicity two moments are very important:

- Active secretion in proximal tubules with the same degree of reabsorption

- Active transport inside the proximal tubules in the antiluminal side with restricted movement of tubular fluids. It is proved that the toxic agent can pass through cell membranes, entering in lysosomes in nonionised form, so it is trapped in these organelles due to the low $\mathrm{pH}$.

Possible mechanism of nephrotoxicity could be due to interference of the normal lysosomal digestion which leads to lysis of the lysosomal membrane, and transfer of the acid hydrolyses in the cell cytosol of the proximal tubules, which is manifested latter with necroses.

As possible pathways for entrance in the epithelial cells are noted:

- Apical membrane transportation via pinocytosis with adequate drug uptake (chemotherapeutics, aminoglycosides, cephalosporins, diuretics i other toxic drugs) inside the lysosomes.

- Apical membrane transportation via some unknown way which complements the process of pinocytosis.

- Basolateral membrane transportation.

\section{Material and Methods}

The diagnosis of the patients included in the study is based on the revised diagnostic criteria for classification of Rheumatoid arthritis proposed in 1987 by the American Association for Rheumatism (ARA) [17]. In order to include the patient in the group with RA, he should fulfill at least 4 of the 7 criteria. Criteria 1-4 should persist at least 6 months. 
In the study are included 35 patients with RA ( 20 women, 15 men), treated with Paracetamol, and 35 patients with RA (22 women, 13 men) treated with Ketoprofen. Their average age is 55,53 years $( \pm 8,42)$ range $(40-65$ years), in the group treated with Paracetamol, while 53, 24 years $( \pm 10,36)$ range (29-65 years) in the group treated with Ketoprofen. Mean disease duration from the beginning is 40,11 months ( $\pm 40,23$ months), range (1-168 months). None of the patients have previous or current history of renal disease. None of the patients previously used NSAIDs. Other patients negated using of other drugs such as golden salts, antibiotics or diuretics. Specimens are collected in the period of 2 years.

\subsection{Inclusion criteria}

In the study are included patients with RA, aged 18-65 years, not previously treated with NSAIDs or DMARDs.

\subsection{Exclusion criteria}

From the study have excluded patients with diseases or conditions that could influence results directly or indirectly:

1. Patient younger than 18 years.

2. Patients with previous history of disease of the spleen, thyroid gland, liver, kidneys, hematological, cardiovascular, neurological, autoimmune and lung diseases.

3. Patients with diabetes mellitus, febrile conditions, acute infections, neoplasms.

4. Patients with uric arthritis, SLE, mixed connective tissue disease, vasculitis.

5. Patients with history of blood transfusion and patients with body overweight.

6. Patients with history of use of drugs from the base line.

7. Patients that in 0 point had increased levels of glucose, serum and urine urea and creatinine, blood hypertension, smokers and blood and enzyme disorders

8. Patients previously treated with salicylates, antibiotics, golden salts or diuretics

9. All the patients took part in this study voluntarily, so the ethical criteria for this study are fulfilled.

\subsection{Clinical Estimation of Disease Activity}

Clinical estimation is made by subspecialist in the field. Disease activity is estimated using DAS 28 index (Disease Activity Score - DAS 28) [18-20]. The index uses mathematical formula to obtain unique composite quantitative score, which consists of: palpable painful joints (maximal niumber 28), swallen joints (maximal niumber 28), Erythrocyte sedimentation rate (ESR) and patient's estimation for disease activity $\quad$ (0-100 mm). Visual Analogue Scale - VAS) and morning stiffness (minutes). DAS 28 index ranges from 0 to 10 and score $<3.2$ qualifies the disease as low active.

\subsection{Laboratory Estimation}

For clinical estimation of the disease, it is necessary to examine following laboratory variables: complete blood count and differencial, reactants of the acute phase, ACPA-antibodies, C-reactive protein (CRP), Rheumatoid factor (RF) and Erythrocyte sedimentation rate (ESR), alcaline phosphatase (AP), aspartat aminotransferase (AST), alanin aminotransferase (ALT), creatin kinase (CK), laktat dehydrogenase (LDH), serum urea, serum creatinin. Urine samples are taken not only for routine analyses, but also for determination of NAG and microalbuminuria. 
2.5 Detection of Microalbuminuria With Immunoturbidimetric Assay (Randox Laboratories Limited)

Principle:

Undissolved sample is added to the puffer with antibodies specific for human serum albumin. The absorbance (340 $\mathrm{nm}$ ) is proportional with the albumin concentration in the urine sample. With the construction of the standard curve from the standard absorbance, one can determine the albumin concentration in the sample. Determination is automatic with the use of DAKO tests.

Urine sample and its storage: The middle stream from the morning urination is taken. It is centrifuged before the use in order to use purified supernatant.

Referent values: Microalbuminuria: $2.0-20.0 \mathrm{mg} / \mathrm{L}$.

2.6 Determination of the Activity of N-Acetyl-B-D-Glucosaminidase (NAG): Colorimetric Assay (Roche)

\section{Principle:}

3-cresolsulfonphthaleinyl-N-acetyl- $\beta$-D-glucosaminide as sodium salt is hydrolyzed from NAG releasing 3-cresolsulfonephthalein, sodium salt (3-cresol purple) which is measured photometrically on $580 \mathrm{~nm}$ wavelenght (Roche Mancheim tests). The examined urine is centrifuged and the supernatant is taken.

Referent values: NAG in urine $0.27-1.18 \mathrm{U} / \mathrm{mmol}$ creatinine

Serum urea is determined with the method "Kassirer".

Referent values: serum urea $3-7,8 \mathrm{mmol} / \mathrm{L}$.

Serum creatinine is determined with the method "Jaffe".

Referent values: serum creatinine $45-109 \mu \mathrm{mol} / \mathrm{L}$; urine creatinine $7-17 \mu \mathrm{mol} / \mathrm{dU}$.

C-reaktiven protein (CRP) is determined with the agglutination assay (Latex CRP test) (BioSystems S.A. Reagens \& Instruments Costa Brava 30, Barcelona, Spain).

Referent values: $<6 \mathrm{mg} / \mathrm{L}$ CRP in serum

Rheumatoid factor (RF) is determined with the agglutination assay (Latex RF test) (BioSystems S.A. Reagens\&Instruments Costa Brava 30, Barselona, Spain).

Referent values: $<8 \mathrm{IU} / \mathrm{ml}$ in serum.

For determination of the Erythrocyte sedimentation rate (ESR) is used quantitative method - Westergren test.

Referent values: For men 7-8mm, for women 11-16mm. 


\subsection{Statistical analysis}

To test the significance of the differences between two arithmetic means i.e.proportions is used the Student t-test. To compare the mean values of certain numerical parameters between two groups was used Wilcoxon-matched test for independent species. Sensitivity and predictivity for positive and negative test of the examined markers is determined with the sensitivity and specificity test. P-value between 0.05 and 0.1 is considered statistically significant. Data analysis is performed with statistical package Statistica 7.0.

\section{Results}

Analyzing the group of patients treated with Paracetamol in comparison with the distribution of patients, according to NAG values in the four samples, one can conclude that NAG values are registered in 20 patients in the 12th week, when the degree of the mean urine NAG value is highest (1.20 \pm 1.04$)$.

Analyzing the group of patients treated with Paracetamol in comparison with the distribution of patients, according to NAG values in the four samples, one can conclude that NAG values are registered in 26 patients in the 12th week, when the degree of the mean urine NAG value is highest $(1.80 \pm 0.33)$.

Testing the significance of the differences in both groups in the 0 (zero) sample in the group of patients treated with Paracetamol, the mean value of the NAG enzymuria is in the range $0.93 \pm 0.48$, while in the group of patients treated with Ketoprofen is $1.59 \pm 0.67$. That shows that Ketoprofen is more potent NAG indicated in comparison with Paracetamol both in range and in the time of appearance (Table 1).

In the group of patients treated with Paracetamol, about the distribution of patients, according to the values of microalbuminuria in the four groups, one can conclude that increased values of microalbuminuria are registered in 5 patients in the $4^{\text {th }}$ week, when the degree of microalbuminuria is highest $14.1 \pm 1.07$.

Analyzing the distribution of patients, according to the values of microalbuminuria in the four samples, in the group of patients treated with Ketoprofen, one can conclude that in 7 patients in the 4th week, when the degree of microalbuminuria is highest $18.80 \pm 0.33$.

Testing the significance of the differences in both examined groups in the zero sample, in the group of patients treated with Paracetamol, mean value of microalbuminuria is in the range $0.53 \pm 0.48$, while in the group of patients treated with Ketoprofen is $0.67 \pm 0.57$. That explains that Paracetamol has identical values of microalbuminuria in comparison with Ketoprofen.

Analysis with the Pearsons c2 test shows that there is a moderate correlation between NAG and microalbuminuria $(r=0.28)$ between the increase of the values of NAG and microalbuminuria in the four samples in the follow up period of 12 weeks in the group of patients treated only with Ketoprofen (Graph $2 \& 4$ ). 
Analysis with the Pearsons c2 test shows that there is a statistical significant correlation $(\mathrm{r}=0.16)$ between the increase of the values of NAG and microalbuminuria in the four samples in the follow up period of 12 weeks in the group of patients treated only with Paracetamol (Graph $1 \& 3$ ).

\begin{tabular}{|c|c|c|c|c|}
\hline \multicolumn{3}{|c|}{$\begin{array}{l}\text { GROUP PARACETAMOL } \\
\qquad \mathbf{N}=35\end{array}$} & \multicolumn{2}{|c|}{$\begin{array}{l}\text { GROUP KETOPROFEN } \\
\qquad \mathbf{N}=35\end{array}$} \\
\hline & $\begin{array}{c}\text { *NAG } \\
+>1.18 \\
(\mathrm{U} / \mathrm{mmol} / \text { creatin }) \\
\text { value }(\mathrm{M} \pm \mathrm{SD})\end{array}$ & $\begin{array}{c}\text { MICROALBUMINURIA } \\
+>20 \\
(\mathrm{mg} / \mathrm{L}) \\
\text { value }(\mathrm{M} \pm \mathrm{SD})\end{array}$ & $\begin{array}{c}\mathrm{NAG} \\
+>1.18 \\
(\mathrm{U} / \mathrm{mmol} / \text { creatin }) \\
\text { value }(\mathrm{M} \pm \mathrm{SD})\end{array}$ & $\begin{array}{l}\text { MICROALBUMINURIA } \\
\qquad \begin{array}{c} \\
(\mathrm{mg} / \mathrm{L}) \\
\text { value }(\mathrm{M} \pm \mathrm{SD})\end{array}\end{array}$ \\
\hline $\begin{array}{c}0 \\
\text { time }\end{array}$ & $\begin{array}{c}1.13 \pm 0.54 \\
13\end{array}$ & $\begin{array}{c}12.91 \pm 10.07 \\
5\end{array}$ & $\begin{array}{c}0.93 \pm 0.48 \\
13\end{array}$ & $\begin{array}{c}16.35 \pm 7.41 \\
5\end{array}$ \\
\hline $\begin{array}{c}4 \\
\text { weeks }\end{array}$ & $\begin{array}{c}1.17 \pm 0.48 \\
18\end{array}$ & $\begin{array}{c}14.1 \pm 1.07 \\
5\end{array}$ & $\begin{array}{c}1.27 \pm 0.47 \\
18\end{array}$ & $\begin{array}{c}18.80 \pm 0.33 \\
7\end{array}$ \\
\hline 8 weeks & $\begin{array}{c}1.19 \pm 0.67 \\
19\end{array}$ & $\begin{array}{c}11.91 \pm 11.23 \\
4\end{array}$ & $\begin{array}{c}1.58 \pm 1.40 \\
23\end{array}$ & $\begin{array}{c}16.50 \pm 9.69 \\
4\end{array}$ \\
\hline $\begin{array}{c}12 \\
\text { weeks }\end{array}$ & $\begin{array}{c}1.20 \pm 1.04 \\
20\end{array}$ & $\begin{array}{c}12.08 \pm 10.68 \\
2\end{array}$ & $\begin{array}{c}1.80 \pm 0.33 \\
26\end{array}$ & $\begin{array}{c}15.50 \pm 8.58 \\
2\end{array}$ \\
\hline
\end{tabular}

Table1. NAG, microalbuminuria in the group of patients with Paracetamol and Ketoprofen.

*NAG - positive value ( $>1.18 \mathrm{U} / \mathrm{mmol} /$ creatin $)$; Microalbuminuria- positive value $(>20 \mathrm{mg} / \mathrm{L})$;

**. Data are expressed as mean values $\mathrm{M} \pm \mathrm{SD}$ and as the number of patients with values in the normal range or above normal .

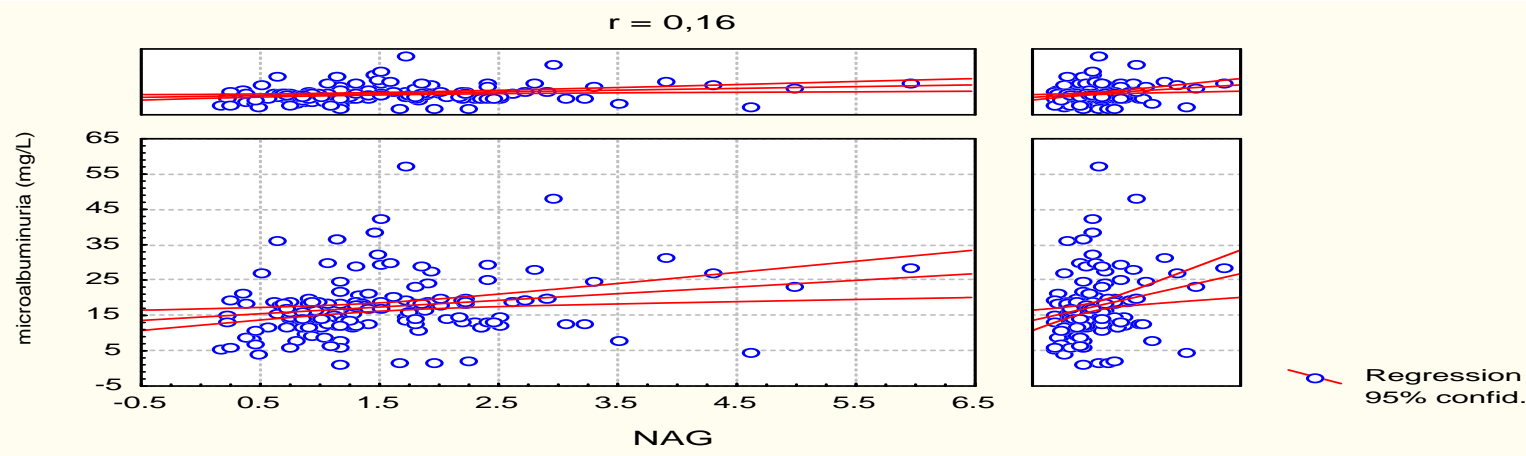

Graph 1. Pearson's coefficient of correlation (r) between the values of NAG and microalbuminuria in the group treated with Paracetamol. There is a weak correlation between NAG and microalbuminuria $(\mathrm{r}=0.16)$. 


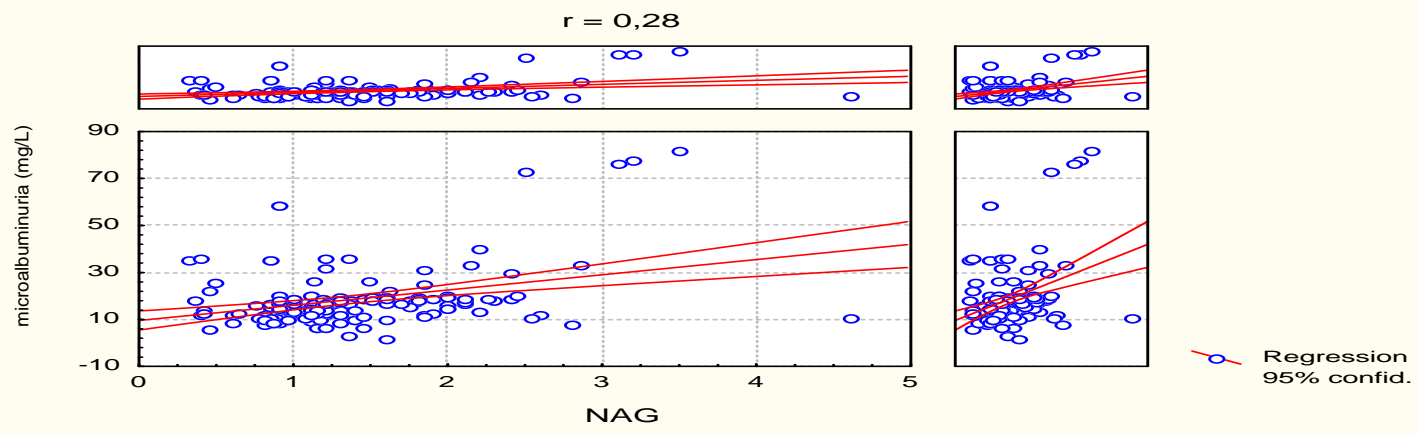

Graph 2. Pearson's coefficient of correlation (r) between the values of NAG and microalbuminuria in the group treated only with Ketoprofen. There is a moderate correlation between NAG and microalbuminuria $(\mathrm{r}=0.28)$.
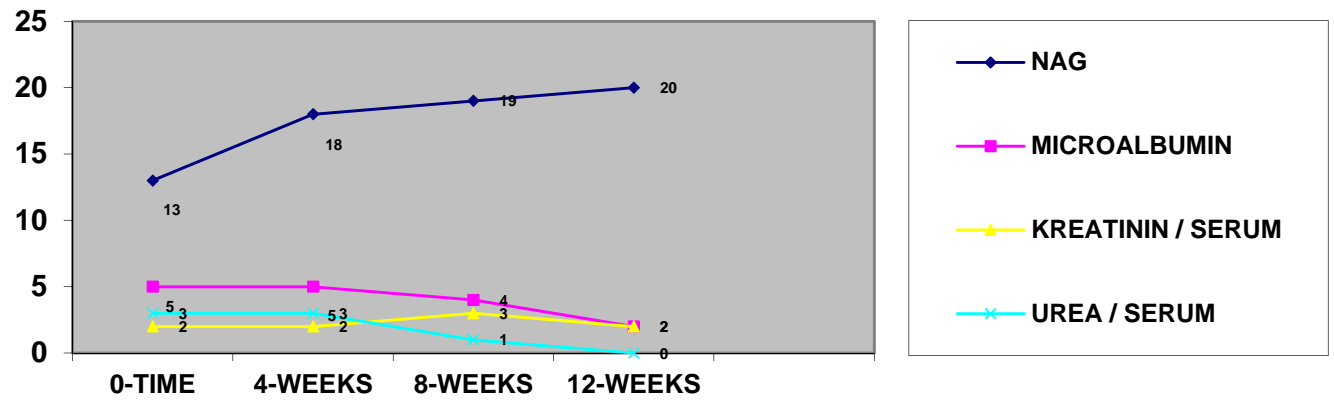

Graph 3. Distribution of patients in the group with Paracetamol according to the increased values of NAG, microalbuminuria and other laboratory variables in the four samples.
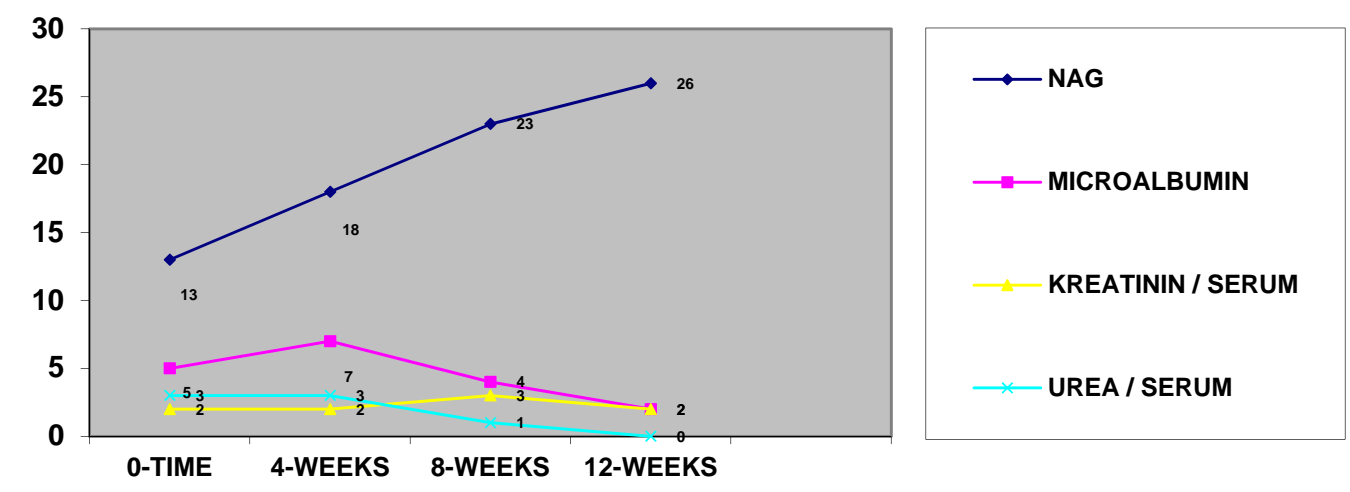

Graph 4. Distribution of patients in the group with Ketoprofen according to initial values of NAG, microalbuminuria and other laboratory variables in the four samples. 


\section{Discussion}

Traditional treatment of RA includes non-steroid anti-inflammatory drugs (NSAIDs), drugs that modify the disease (DMARDs), steroids, immunosuppressive and cytotoxic drugs. Metotrexate in low dose regime is the most frequent drug from the group of DMARDs, while from the group of NSADs the most used drug is Ketoprofen (NiflamR, KetonalR), as well as Paracetamol.

The approach for estimation of the drug nephrotoxicity is possible only with drugs that have dominant proximal tubular excretion, such as Metotrexate, Ketoprofen, Paracetamol and golden salts).

Such approach for estimation of the drug nephrotoxicity is not applicable for other drugs from the base line used in the treatment of RA, such as resochin, sulphasalazine and leflunomide, due to the predominant hepatobiliar secretion. There are not data in the literature for the toxic effect of these drugs on proximal tubular disfunction.

In untreated RA primarily is affected tubular and much less glomerular function (21). Glomerular integrity is basically intact in the examined groups of RA patients with the use of Paracetamol and Ketoprofen. The initial increase in the activity is the result of the changes in cell synthesis and not always enzymuria could be the result of the lytic or necrotic processes.

Paracetamol usually does not trigger significant damage of the renal proximal tubules in most of the examined patients. Nephrotoxicity of Ketoprofen is higher in comparison with Paracetamol.

Ketoprofen is a more potent NAG inductor in comparison with Paracetamol. NAG induction is higher and appears earlier in the use of Ketoprofen in comparison with Paracetamol.

These results correspond with the findings in the literature (22-26). Early detection of the increased NAG enzymuria or appearance of the microalbuminuria before the beginning of the drug use could be useful compared with the possible toxicity probably related to impaired renal clearance.

There is not any change in the clinical indicators of the renal function compared with the degradation products of the nitrogen metabolism (serum creatinin, serum urea) in the course of disease. The least sensitive markers for early nephrotoxicity caused by Ketoprofen and Paracetamolot are the serum creatinin and urea concentration, as well as the level of calculated creatinin clearance. These tests point out the changed, decreased glomerular filtration, but not changes in the renal tubular function. We think that the use of these parameters could be applicable in the clinical

practice in cases with long term therapy with Ketoprofen, Metotrexate and Paracetamol combined with antibiotic therapy, when they can show impairment of the gromerular filtration.

\section{Conclusion}

Results obtained in our study proved the safety of Paracetamolot and Ketoprofenot in the treatment of RA patients. 
As measures taken for prevention of nephrotoxicity are: follow up of the renal function by regular check up of the enzyme activity in the urine, estimation of the effectiveness of the exfoliative turn over on tubular cells, avoidance of frequent use of drugs and individual adjustment of the drug dosage.

As the complementary diagnostic tools, determination of the urine NAG together with urinary creatinin excretion could be more sensitive tests for renal damage in patients with RA.

\section{Conflict of Interest}

The authors declare no conflict of interest.

\section{References}

1. Moriguchi J, Ezaki T, Tsukahara T, Furuki K, Fukui Y, et al. Comparative evaluation of four urinary tubular dysfunction markers, with special references to the effects of aging and correction for creatinine concentration. Toxicol Lett 143 (2003): 279-290.

2. Banday AA, Farooq N, Priyamvada S, Yusufi AN, Khan F. Time dependent effects of gentamicin on the enzymes of carbohydrate metabolism, brush border membrane and oxidative stress in rat kidney tissues. Life Sci 82 (2008): 450459 .

3. Neufeld EF. Natural history and inherited disorders of a lysosomal enzyme, b hexosaminidase. J Biol Chem 262 (1989):10927-10930.

4. Robinson D, Stirling JL. N-Acetylglucosaminidase in human spleen. Biochem J 107 (1968): 321-327.

5. Price RG, Dance N. The demonstration of multiple heat stable forms of N-acetyl-b glucosaminidase in human serum. Biochim Biophys Acta 271 (1972): 145-153.

6. Lockwood TD, Bosmann HB. The use of N-acetyl-glucosaminidase in human renal toxicology. 1. Partial biochemical Characterization and excretion in human and release from the isolated rat kidney. Toxicol Appl Pharmacol 49 (1979): 323-336.

7. Gibey R, Dupond JL, Henry JC. Urinary N-acetyl-D-glucosaminidase isoenzyme profile: a tool for evaluating nephrotoxicity of aminoglycosides and cephalosporins. Clin Chim Acta 137 (1984): 1-11.

8. Paigen K, Peterson J. Coordinacy of lysosomal enzyme excretion in human urine.J Clin Invest 61 1978):751-762.

9. Bourbouze R, Bernard M, Baumann FCh, Perez-Gonzales N, Martin-Barientos J, et al. Subcellular distribution of the N-acetyl-b-D-glucosaminidase isoenzymes from rabbit kidney cortex. Cell Mol Biol 32 (1984): 67-74.

10. Burton CJ, Walls J. Proximal tubular cell, proteinuria and tubulo-interstitial scarring. Nephron 68 (1994): 287-293.

11. Chiu JSP. Models used to asses renal function.Drug Devel Res 32 (1994): 247-255.

12. Price RG. Measurement of $\mathrm{N}$-acetyl- $\beta$-glucosaminidase and its isoenzymes in urine, methods and clinical applications. Eur J Clin Chem Clin Biochem 30 (1992): 693-705.

13. Price RG. The role of NAG (N-acetyl- $\beta$-D- glucosaminidase) in the diagnosis of kidney disease including the monitoring of nephrotoxicity.Clin Nephrol 38 (1992): 14-19.

14. Tucker SM, Pierce RJ, Price RG. Characterization of human N-acetyl- $\beta$-D glicosaminidase isoenzymes as an indicator of tissue damage in disease.Clin Chim Acta 102 (1980): 29-40. 
15. Morgensen CE, Chachati A, Christensen CK, Close CF, Deckert T, et al. Microalbuminuria: an early marker of renal involvement in diabetes. Uremia Invest 9 (1986): 85-95.

16. DJ F Rowe A Dawnay G F Watts. Microalbuminuria in diabetes mellitus: review and recommendations for the measurement of albumin in urine. Ann Clin Biochem 27 (1990): 297-312.

17. Van Gestel AM, Prevoo ML, van 't Hof MA, van Rijswijk MH. Development and validation of the European league against rheumatism response criteria for rheumatoid arthritis. Comparison with the preliminary American college of rheumatology and the world health organization/international league against rheumatism criteria. Arthritis Rheum 39 (1996): 34-40.

18. Prevoo ML, van 't Hof MA, Kuper HH, van Leeuwen MA. Modified disease activity scores that include twentyeight-joint counts. Development and validation in a prospective longitudinal study of patients with rheumatoid arthritis. Arthritis Rheum 38 (1995): 44-48.

19. Balsa A, Carmona L, Gonzalez-Alvaro I, Belmonte MA. Value of DAS-28 and DAS 28-3 as compared to ACRdefined remission in rheumatoid arthritis. J Rheumatol 31 (2004): 40-46.

20. Prevoo ML, van Gestel AM, van T Hof MA, van Rijswijk MH. Remission in a prospective study of patients with rheumatoid arthritis. American rheumatism association preliminary remission criteria in relation to the disease activity score. Br J Rheumatol 35 (1996): 1101-1105.

21. Spasovski D, Gruev T, Marina N, et al. The diagnostic value of N-acetyl-b-D-glucosaminidase and microalbumin concentrations in rheumatoid arthritis. JMB 26 (2007): 300-308.

22. Boers M, Dijkmans BA, Breedveld FC, Camps JA, Chang PC, et al. Subclinical renal dysfunction in rheumatoid arthritis. Arthritis Rheum. 33 (1990): 95-101.

23. Knudsen LS, Klarlund M, Skjodt H, Jensen T, Ostergaard M, et al. Biomarkers of inflammation in patients with unclassified polyarthritis and early rheumatoid arthritis. Relationship to disease activity and radiographic outcome. $\mathrm{J}$ Rheumatol 35 (2008):1277-1287.

24. Koseki Y, Terai C, Moriguchi M, Uesato M, Kamatani N. A prospective study of renal disease in patients with early rheumatoid arthritis. Ann Rheum Dis 60 (2001): 327-331.

25. Marchewka Z, Przewłocki M, Lepka M, Długosz A, Kochman K. Selected biochemical parameters of urine in the evaluation of paracetamol nephrotoxicity. Przegl Lek 63 (2006): 1299-1303.

26. da Silva Melo DA, Saciura VC, Poloni JA, Oliveira CS, Filho JC, et al. Evaluation of renal enzymuria and cellular excretion as an marker of acute nephrotoxicity due to an overdose of paracetamol. Clin Chim Acta 373 (2006): 8889.

This article is an open access article distributed under the terms and conditions of the

Creative Commons Attribution (CC-BY) license 4.0 